\title{
Review Article Proposals Solicited for the Journal of Electronic Materials; Submit Nominations for New TMS Award
}

\section{Journal of Electronic Materials Seeks Proposals for Invited Review Articles}

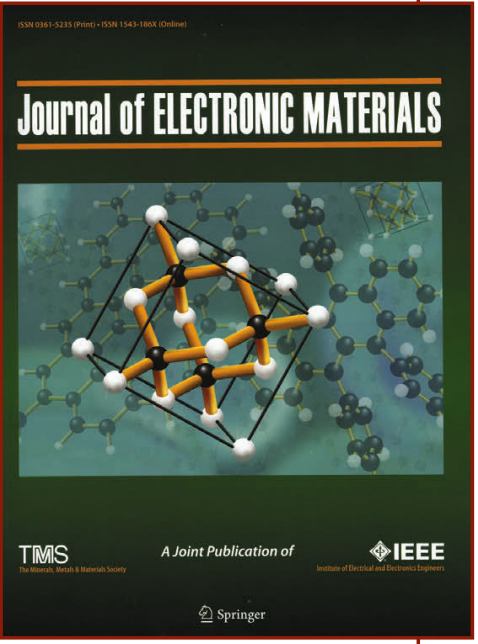

The Journal of Electronic Materials $(J E M)$ is soliciting proposals for invited review articles on emerging applications of electronic materials. JEM reports on the science and technology of electronic materials, publishing articles of interest on semiconductors, magnetic alloys, dielectrics, ferroelectrics, photonic materials, and nanoscale materials.

For this call, review articles of particular interest will provide a new perspective and in-depth review to both non-specialists and specialists, with emphasis on emerging applications of electronic materials

Topics of interest include recent

member news

Share the good news about your professional accomplishments! Contact Kaitlin Calva, JOM Magazine Managing Editor, atkcalva@tms. org. Please note that only news submitted by current TMS members will be considered. experimental and theoretical research including, but not limited to:

- Electronic materials for energy conversion and storage

- Electronic materials for novel memory, logic, and interconnect applications

- Graphene and other 2D electronic materials

- Electronic materials for photonic interconnects and novel wavelength tunable light emission applications

- Electronic materials for power electronics and smart grid applications

- Bioelectronics materials, including applications to COVID-19 challenges
For the journal to invite a review article, the lead author should submit a proposal containing the information listed below (within a two-page limit):

- Topic or a tentative title for the review article

- Author names and affiliations, including contact information for the lead author

- Five selected relevant publications per author in the topical area of the proposal

- An abstract (less than 250 words) summarizing the background and motivation for the review article

- A comprehensive list of previously published articles (approximately 25 or more) to be discussed in the review. Ideally, the majority of these articles are by authors others than the proposing authors

If invited, a review article should be submitted within three months of the invitation date. Review articles will be peer reviewed in accordance with the high standards of JEM.

Review article proposals should be e-mailed directly to the Senior Editor, John Baniecki, at jbanieck@slac.stanford.edu. Additional journal details are available at www.springer.com/11664.

\section{Superalloys Archive Expands}

The Superalloys Proceedings Archive has added Superalloys 2016 to its online collection. The archive is free to all users through the support of the International Symposium on Superalloys Committee. To date, it houses more than 1,000 technical articles encompassing the history of these important materials. Visit www.tms.org/SuperalloysArchive to access the newly added papers and all other publications in the archive.

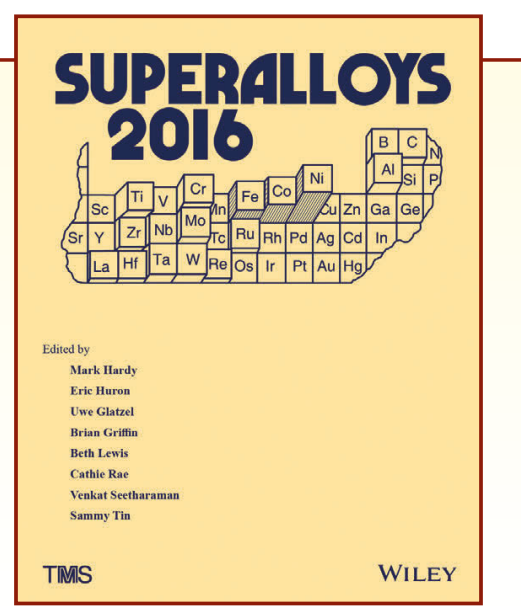




\section{Newly Funded Award Honors Donald Sadoway}

TMS members can now submit nominations for the new Sadoway Materials Innovation and Advocacy Award for mid-career professionals. Named for Donald Sadoway, John F. Elliot Professor of Materials Chemistry at the Massachusetts Institute of Technology (MIT), the award will recognize individuals who have made impactful and broad materials science and engineering achievements and possess a unique ability to champion their work and the field as a whole through education, public advocacy, or entrepreneurship.

To nominate a colleague for the inaugural award in 2022, applications must be submitted to TMS staff at awards@tms.org by April 1, 2021. The award recipient will be recognized at the TMS Annual Meeting \& Exhibition and will receive a $\$ 3,500$ prize.

Sadoway's former students, colleagues, and associates raised the award funds to honor Sadoway's influence on them, the MIT Department of Materials
Science and Engineering, and the global materials science community. Additional details are available at www.tms.org/ SadowayAward.

This award joins more than 15 other Society-level TMS awards, including several that are administered by TMS on behalf of American Institute for Mining, Metallurgical, and Petroleum Engineers (AIME), TMS's antecedent organization. These honors recognize the outstanding achievements of some of the most accomplished and promising materials scientists and engineers in the world. For more information on all awards, as well as histories on select named awards, visit www.tms.org/Awards.

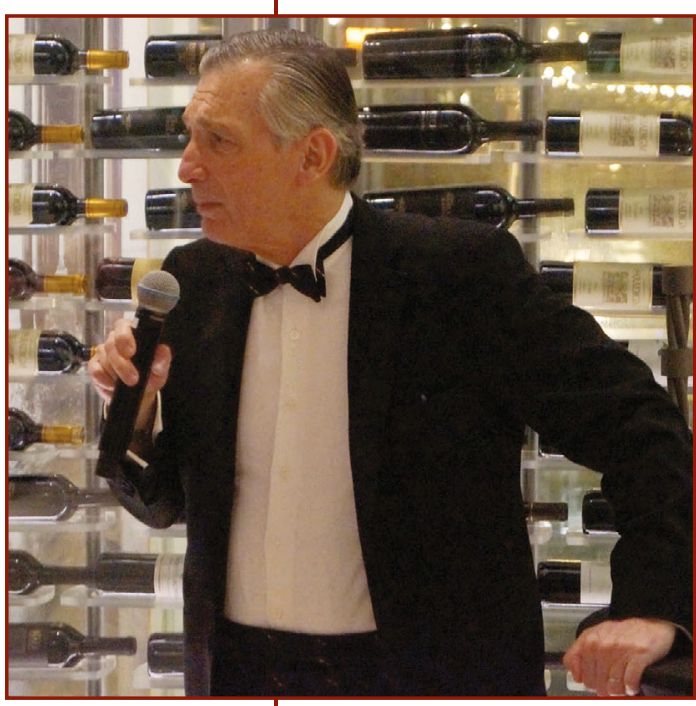

Donald Sadoway thanks his past students, colleagues, and supporters for starting a new award in his honor at the TMS

Foundation Donor Dinner in February 2020.

\section{New Reserach Collaboration Features TMS Member}

TMS member Nikhil Gupta, a professor in the Tandon School of Engineering at New York University (NYU), was awarded a multi-year collaboration with Anton Paar USA. Gupta's team at NYU will conduct its research using a high-end dynamic mechanical analysis (DMA) device from Anton Paar. Their research focus will build on a recently awarded patent for fundamental advancements in the method of processing data gathered by the DMA device, which allows the conversion of viscoelastic properties to elastic properties. These new research goals join the team's current focus on new security methods of 3D printing, developing filaments of advanced composites, and using machine learning methods for materials characterization.

Gupta has been an active member of TMS for more than 20 years, serving as a $J O M$ advisor and on several technical committees, as well as on the Structural Materials Division (SMD) Council. In 2013, he received a TMS SMD Young Leaders Professional Development Award. Earlier this year, he was named a TMS Brimacombe Medalist, "for innovations in the development of lightweight porous materials and for commitment to educating the public about the impact of materials research on society."

\section{In Memoriam: Lewis R. Aronin}

TMS extends condolences to the family, friends, and colleagues of Lewis R. Aronin, who passed away at the age of 100 on May 21, 2020. Upon earning his B.S. in applied physics from Massachusetts Institute of Technology (MIT), Aronin spent several years in industry working for Waltham Watch Company before retuning to MIT as research staff on the MIT Metallurgical Project. When Nuclear Metals assumed the project in 1958, Aronin returned to industry, becoming the leader of physical metallurgy and manager of metallurgical research until 1966. He later joined Kennicott Copper Corporation Ledgmont Laboratory as a consultant before moving to the Army Materials Technology Laboratory, where he worked until 1990. During his retirement, Aronin volunteered for MIT's Age Lab, in the 85+ Lifestyle Leaders community panel.

A longtime member of TMS, Aronin was originally a member of TMS's antecedent organization, the American Institute of Mining, Metallurgical, and Petroleum Engineers. 